\title{
POBREZA Y MARGINACIÓN EN LA CASTILLA BAJOMEDIEVAL NOTAS SOBRE EL EJERCICIO DE LA CARIDAD EN CUENCA \\ A FINES DE LA EDAD MEDIA
}

\author{
JORGE DIAZ IBÁÑEZ \\ Universidad Complutense (Madrid)
}

\begin{abstract}
SUMARIO
Introducción.- I. La red hospitalaria: 1. Los hospitales urbanos.- 2. Los hospitales nurales. La casa-hospital de Fuentes.- 3. La iniciativa concejil.II. El Arca de la Limosna: 1. La caridad del claro y los laicos.- 2. La administración del patrimonio del Arca de la Limosna.- III. Conclusión.
\end{abstract}

\section{INI'RODUCCIÓN}

Hace ya algo más de veinte años, en el Congreso Internacional de Ciencias Históricas celebrado en Moscú en el verano de 1970, el profesor francés M.Mollat llamó la atención de los historiadores con su ponencia sobre "Los pobres en la Edad Media". A partir de aquella fecha se han multiplicado los trabajos relativos al mundo de los marginados. Pobres, enfermos, vagabundos, miserables...Todo un grupo variopinto de desposerdos de la fortuna que ha sido objeto de estudio, en mayor o menor medida, por parte de numerosos medievalistas de los últimos veinte años.

En tierras peninsulares el punto de partida de esta preocupación historiográfica fue el Congreso hispano-luso, celebrado en Lisboa en septiembre de 1972, que tuvo como título "A pobreza e a assistencia aos pobres na Peninsula Iberica durante Idade Media"'. Es a partir de este mo- 
mento cuando el tema comienza a despertar cierto interés para la historiografía hispánica, a pesar de lo cual puede afirmarse que en la actualidad es aún bastante lo que queda por hacer en este ámbito de trabajo, en el cual con frecuencia se hace necesaria la exhumación de una diversificada tipologia de fuentes documentales manuscritas que en ocasiones se hallan contenidas en centros archivisticos de difícil acceso ${ }^{2}$.

El tema de la pobreza formaba inexcusablemente parte de la conciencia medieval y, más tarde, a lo largo de los siglos del Antiguo Régimen, frecuentemente se nos presentará con los mismos planteamientos de la época bajomedieval.

A fines de la Edad Media la pobreza ofrecía rasgos poco definidos, tanto en el ámbito de Occidente como en el más específico de Castilla: bajo el concepto de "pobre" se reúnen condiciones muy variopintas y diversas, tanto en lo que respecta a sus plasmaciones concretas como en lo relativo a la terminología empleada para describirlos. Asi, durante la Baja Edad Media para referirse al "pobre" se hablará de indigentes, mendigos, miserables, famélicos, hambrientos, leprosos, tontos, idiotas, simples, imbéciles, esclavos, viejos, viudas...Por todo ello con frecuencia resulta difícil a través de la documentación de la época determinar a qué situación social concreta se está aludiendo.

\footnotetext{
'"A pobreza e a assistencia aos pobres na Peninsula Iberica durante Idade Media. Actas de la Primeras Jomadas luso-españolas de Historia Medieval (IX-1972)", 2 vols., Lisboa, 197374.

${ }^{2}$ Una visión de conjunto más reciente sobre el tema es la que nos ofrece la obra de $\mathbf{C}$. LOPEZ ALONSO, La pobreza en la España Medieval, Madrid, 1986. Este trabajo, a pesar de estar basado sobre todo en fuentes publicadas, muchas de ellas literarias y jurídicas, resulta útil al ofrecer una amplia panorámica global sobre el tema durante el trancurso de todo el Medievo peninsular. Otros trabajos de interés que cabe señalar son los siguientes: J. SANCHEZ HERRERO, Cofradias, hospitales y beneficencia en algunas dibcesis del valle del Duero. Siglos XIV y XV, "Hispania", 126 (1974) (Este estudio se centra en las diócesis de León, Astorga, Zamora, Salamanca, Ciudad Rodrigo y Palencia); L. MARTINEZ GARCIA, La asistencia a los pobres en Burgos en la Baja Edad Media. El Hospital de Santa Maria la Real.1341-1500, Burgos, 1981; del mismo autor El Hospital del Rey de Burgos. Un seftorio medieval en la expansión y en la crisis (siglos XIII y XIV), Burgos, 1986.; S. AGUADE NIETO, Crisis de subsistencia, rentas eclesiásticas y caridad en la Castilla de la segunda mitad del siglo XV, "En la España Medieval", 2 (1982); R. IZQUIERDO BENITO, Bienes y rentas del Hospital de la Misericordia de Toledo durante la primera mitad del siglo XV, "En la España Medieval", 1 (1980); M. CANTERA MONTENEGRo, El oficio de la limosnería en Santa Maria la Real de Nájera (siglos XI-XV), "En la España Medieval", 4 (1984); H. RODRIGUEZ DE GRACIA, Pobreza y "beneficencia en la provincia de Toledo (1500-1800), Toledo, 1983. Asimismo, también resultan de interés las "Actas del III Coloquio de Historia Medieval de Andalucía" (Jaén, 1984), donde varias comunicaciones tocaron el tema.
} 
Otro problema historiografico sobre el que conviene hacer hincapié es el referente a la actitud global de la sociedad ante el "pobre". La sociedad bajomedieval y la del Antiguo Régimen se plantearán el tema de la pobreza no desde la perspectiva de una problemática social, sino como cuestión moral, propia de una reflexión teológica que entra en el ámbito de lo religioso. La inquietud del pecado, el temor a la muerte, la incertidumbre de la salvación, características de la mentalidad religiosa europea de finales de Medievo, se reflejan en los testamentos de la época y en la importancia que los testadores casi siempre otorgan a la ayuda al pobre. La atención a éste a través de la limosna constituye un elemento que contribuye, según la ideología de aquel tiempo, a facilitar la salvación de los más pudientes ${ }^{3}$. Por otro lado, ya en el IV Concilio de Letrán de 1215 se habra instado a los fieles a ejercer la caridad y limosna hacia el pobre 4 .

No obstante, todo lo dicho no excluye que ante la presencia de la pobreza se produzca una clara tendencia hacia la institucionalización de la asistencia al pobre, tratando de establecer un marco legal donde se intenta ubicar el problema de la pobreza. Incidencias biológicas (vejez, enfermedad), incidencias de coyuntura y crisis, incidencias sociales...Unas y otras tuvieron como motor y agente principal la peculiar estructura del sistema feudal. Si hasta el siglo XII la pobreza no habra pasado de ser, para los moralistas y poderes públicos, un problema marginal fácilmente controlado y atendido por las instituciones eclesiásticas, a partir del siglo XIII y sobre todo desde el XIV se convertirá en un fenómeno permanente. Asi, al lado del pobre "natural" (vejez, enfermedad), conocido en la ciudad o en la aldea, imposibilitado para el trabajo y digno de compasión, irrumpirá con fuerza, al amparo de la crisis política, económica o demográfica, el pobre "ocasional", el vago y el delincuente, cuya imagen, a diferencia de los otros, infundía temor y recelo. Como medida de defensa, y para encubrir conflictos sociales latentes, el poder sentirá la necesidad de controlar la fuerza potencial de la masa de desheredados. A ello tenderán las frecuentes disposiciones legales emanadas de las Cortes de los últimos siglos medievales, invitando a trabajar al ocioso y al mendigos.

\footnotetext{
239.

${ }^{3}$ M. Moldat, Pobres, humildes y miserables en la Edad Media, México, FCE, 1988, p.

4 Bbidem, p.117.

${ }^{5}$ Es de destacar en este punto el trabajo de C. LÓPEZ ALONSO, Conflictividad social y pobreza en la Edad Media segün las Actas de las Cortes castellano-leonesas, "Hispania", 140
} 
Pero el sistema más difundido de control, canalización e institucionalización de la asistencia al indigente lo constituirán los hospitales junto con las cofradías y "Arcas de Misericordia", de cuyo mantenimiento serán responsables tanto elementos laicos como eclesiásticos. El objeto de este trabajo radica, precisamente, en esbozar unos breves apuntes sobre el desarrollo de este proceso institucionalizador en la ciudad de Cuenca y en algunos lugares de su diocesis, proceso que estará en consonancia con una mentalidad que acepta la pobreza como un fenómeno necesario e inevitable cuya presencia se justifica por constituir la mejor prueba para el desarrollo de la caridad cristiana.

El presente ensayo no pretende, ni mucho menos, agotar todas las posibilidades de estudio que el tema ofrece para el caso especifico de la ciudad de Cuenca, sino tan sólo apuntar algunos breves datos, pero a su vez muy esclarecedores, obtenidos a raiz de la documentación consultada, dejando para otra ocasión un análisis mucho más completo y pormenorizado sobre el tema.

\section{LA RED HOSPITALARIA}

\section{Los hospitales urbanos}

El término medieval "hospital", a diferencia del actual, tuvo un significado más amplio, de triple carácter: el de "hospederfa" para albergue de viajeros y peregrinos de paso, el de "asilo" donde se recogfa y mantenfa a los pobres, y el de "hospital" propiamente dicho, para atención y cuidado de los enfermos.

En general, casi todos acogieron indistintamente a individuos de cada una de las tres categorfas. No fue extraño, sin embargo, que un determinado hospital tuviera preferencias sobre cualquiera de ellas. A veces se primaba la atención al peregrino ${ }^{6}$. Otros centros hospitalarios, ya desde el momento de su fundación, se especializaron en determinadas enfermedades,

(1978), pp. 475-567.

- Un ejemplo de ello lo encontramos en el Hospital del Rey de Burgos, cuya función primordial fue la de albergue de peregrinos. 
como la lepra, la sarna, la tiña, etc. En todo caso primaba, como fin especifico de la institución hospitalaria, la función benéfica.

Durante el período bajomedieval destacará en Occidente, en primer término, el elevado número de fundaciones hospitalarias, las cuales se concentrarán sobre todo en las zonas más urbanizadas. En la Corona de Castilla también se observa la misma tendencia?.

La ciudad de Cuenca tampoco será ajena a este proceso institucionalizador de la asistencia al pobre, en el cual los hospitales jugarán un papel de importancia capital.

El primer hospital que se fundo en Cuenca fue el de Santiago, dependiente de la Orden Militar del mismo nombre, y cuya finalidad primordial en un principio, aunque si en épocas posteriores, no fue la asistencia al enfermo ni al pobre propiamente dichos, sino ante todo la redencion de cautivos cristianos que se hallaban en tierras musulmanas. ${ }^{8}$. Pese a la creencia tradicional, el hospital de Santiago de Cuenca fue fundado por iniciativa real. Aunque no se haya conservado ningún documento fundacional ni gozara de privilegios reales tan explícitos como el de Toledo, es necesario admitir como segura esta hipotesis que desarrolla José Luis Martín, basada en la interpretación del documento que siempre se ha creído origen del hospital. Asi, en 1182, Tello Pérez y Pedro Gutiérrez con sus esposas dan a la Orden todo lo que poseran en Cuenca y su término, excepto una yugada de tierra que tenía Pedro Gutiérrez en la villa de Olmedilla y las propiedades de Tello Pérez en la aldea de Portela; en este documento ya se admite explícitamente la previa existencia del hospital, quizá con excesivas dificultades materiales como para desarrollarse eficazmente?

\footnotetext{
${ }^{7}$ En Córdoba, por ejemplo, están documentados más de 30 hospitales. Astorga contaba al menos con 20 , de los que 16 pertenecían a cofradías de la ciudad, siendo la mayor parte de fundación bajomedieval. Lo mismo ese observa en otras ciudades como Zamora, Palencia, Valladolid, Burgos, Sevilla o Madrid.

- El hospital de Santiago de Cuenca, tras haber pasado por diversos avatarea a lo lango de su prolongada existencia, aún sigue funcionando en la actualidad, y la miaión que hoy ejerce es, esencialmente, de carácter benéfico-esistencial. Sus fọndos documentales hoy en día 20 encuentran en el Archivo Histórico Nacional de Madrid, aunque una pequeria parte se halla en manos de particulares.

' Los donàntes afirman que hacen tal concesión en presencia del rey Alfonso "per mandatum et consilium eiusdem, qui fuit dator istius hereditatis et extat huius hospitalis prenominati ordinis fundator et gubemator". Por otra parte, el hospital fue construído en la "llanura entre el camino y el Júcar" que había dado Alfonso VIII a la Orden en 1177. La tradición atribuyó siempre la fundación a Tello Pérez y Pedro Gutiérrez, a pesar de que en realidad fue fundado por iniciativa regia. J. L. MARTIN RODRfGUEZ, Origenes de la Orden Militar de Saniago,
} 
En otros lugares del obispado tambien se crearán hospitales santiaguistas destinados a la redención de cautivos. El hospital de Moya se fundo en 1211, y hacia 1238 ya habla sido asimilado por el de Cuenca. El de Alarcon, fundado hacia 1203, gozó de una mayor independencia; su base económica fue poco consistente y acabó por integrarse también en el de Cuenca en fecha tardía, entre 1480 y 1500 . Pero sin duda fue el hospital de Cuenca el que tuvo mayor importancia desde el primer momento ${ }^{10}$.

A este respecto resulta muy significativa la concesión en 1184 por el primer obispo de Cuenca, don Juan Yáñez, de cuarenta dras de indulgencia a los que ayudasen con sus limosnas al hospital de Cuenca; además es probable que su influencia pesase en la concesión de limosnas por parte de ciudadanos particulares, asi como de un impuesto municipal por el que el concejo de Cuenca se obligaba a contribuir al sustento del hospital, cuestion esta última que pronto daria lugar a serios altercados y disputas entre los santiaguistas y las autoridades municipales ${ }^{11}$.

Pero será sobre todo a partir del siglo XIV, y de forma más manifiesta durante la siguiente centuria, cuando la red hospitalaria inicie su verdadero desarrollo en la ciudad de Cuenca, as 1 como en ciertos enclaves de la diocesis ${ }^{12}$.

Sabemos que a mediados del siglo XIV se fundo en Cuenca el convento de San Antonio Abad. Los llamados "Antoneros" eran en realidad

1170-1195, Barcelona, 1974, p. 111. (Tomado de P. IRADIEL MURUGARREN, Bases económicas del hospital de Santiago de Cuenca: tendencias del desarrollo económico y estructura de la propiedad agraria, "Anuario de Estudios Medievales", 11 (1981), p. 184).

10 P. IRAdiel Murugarren, Op. cit., pp. 184-185.

" D.W. Lomux, La Orden de Santiago y el obispo de Cuenca en la Edad Media, "Anuario de Estudios Medievales", 12 (1982), p. 305.

12 Para el siglo XIII también se conserva un testimonio documental que alude a la existencia en algún lugar de la diócesis de Cuenca, ya durante la primera mitad de esta centuria, de un convento y hospital de Santa Cristina. Se trata de un documento prácticamente ilegible y en pésimo estado de conservación, datado al parecer en Huete a 16 de marzo de 1230 (la data apenas se lee), a través del cual Navarro, prior del convento y hospital de Santa Cristina, reconoce haber recibido del obispo de Cuenca los dos tercios de los ingresos de las iglesias de Palomares y Huertavellida, reservándose el prelado su tercio privativo( Archivo Catedralicio de Cuenca -en adelante ACC-, caja 4, n⿳ 67). En el documento no se especifica en qué lugar de la diocesis 20 encontraba dicho convento-hospital, aunque al estar datado el documento en la ciudad de Huete y encontrarse los lugares de Palomares y Huertavellida en el término de dicha ciudad, es probable que el mencionado hospital estuviese en Huete o sus proximidades. No obstante, esto ultimo sólo debe ser considerado como una vaga hipótesis que, hoy por hoy, en modo alguno so puede demostrar fidedignamente, dada la carencia de información al respecto. 
hospitalarios encargados de atender a los enfermos del "fuego de San Antón". Su Orden habla sido fundada en 1095 en Vienne, y en 1297 serían convertidos en una congregación de canónigos regulares. En Castilla Alfonso XI y Enrique II les otorgarian su decidida proteccion. Fue hacia 1345 cuando se asentaron en Cuenca, extramuros de la ciudad y junto a una orilla del río Júcar. La comunidad se componía de un comendador y de cuatro o cinco legos que servian el hospital y recogian las limosnas que les daban los fieles, pues tenian privilegios reales para poder pedir en todo el reino de Castilla ${ }^{13}$. Es probable que la ganaderfa tuviese un peso importante en la economía de este pequeño centro hospitalario, pues el 10 de junio del año 1400 Enrique III confirmará todos los privilegios concedidos por sus antecesores a la Orden de San Antón de Cuenca sobre exención de todo pecho a sus ganados, los cuales podrán pastar libremente por todo el reino $^{14}$.

Este centro hospitalario, de dimensiones relativamente modestas, subsistiría hasta el 22 de mayo de 1791, año en que, en virtud de una bula de Pfo VI, lo extinguio el obispo de Cuenca don Felipe Antonio Solano, secularizando a los cuatro legos que en aquel momento habia ${ }^{15}$.

Cerca del convento de los Antoneros sabemos de la existencia, ya desde fines de la Edad Media, de los hospitales de San Lázaro y San Jorge, destinados principalmente a la atención de enfermos pobres. Hubo, asimismo, un hospital de Santa Lucia, para curación de mujeres, y un hospital de San Sebastián, fundado por el obispo Fray Lope de Barrientos (1445-1469), destinado a la atención de hombres pobres y enfermos, encontrándose ambos situados en el terreno que posteriormente ocuparfa el convento de las Bernardas. Otro centro hospitalario importante fue el de Santa Quiteria, que se encontraba situado cerca de la parroquia de San Miguel, mientras que el de San Francisco, San Pedro y San Pablo se localizaba junto a la parroquia de Santa Marfa ${ }^{16}$, y dependía de la cofradfa del mismo nombre.

Sobre esta última poseemos numerosos datos, gracias a un voluminoso libro de cuentas que actualmente se conserva en el Archivo Diocesano

${ }^{13}$ T. MUÑOZ y SOUVA, Noticias de todos los ilustres obispos que han regido la diócesis de Cuenca, Cuenca, 1860, pp. 110-111.

${ }^{14}$ Archivo Histórico Nacional, sección de Microfilmes, rollo 14212.

15 T. MUÑoz Y SOUVA, Op. cit., p. 111.

16 Ibidein, p. 110. 
de Cuenca. El hospital de San Francisco, San Pedro y San Pablo de la ciudad de Cuenca, tal como se acaba de señalar, era un centro dependiente del cabildo-cofradía del mismo nombre, y estaba situado cerca de la parroquia de Santa Marfa la Nueva. El cabildo lo inegraban numerosos cofrades laicos, tanto hombres como mujeres, a cuyo frente habla un prior, cargo que duraba un año. Otros cargos importantes de la cofradía eran los de limosnero, encargado del hospital, tesorero y escribano. Todos sus integrantes eran vecinos de Cuenca, en su mayor parte parroquianos de Santa Marfa la Nueva, y se solían reunir en el local de la hermandad los Domingos o días de fiesta por la mañana para tratar diversos asuntos de carácter administrativo relacionados con las acciones benéficas que corrían a cargo de la cofradía. Cabe destacar la importante presencia de plateros entre sus integrantes $y$, además, dado que en la collación de Santa María la Nueva (que antes habia sido sinagoga judfa) vivian numerosos neoconversos del judaísmo, es probable que algunos de los cofrades del cabildo perteneciesen a este grupo social.

Al menos desde la segunda mitad del siglo XV, consta que la cofradía tenía un hospital cerca de Santa María la Nueva, parroquia que también era la sede principal de la hermandad y en la que se decian misas y responsos por los cofrades fallecidos.

Desde 1440 se conservan las cuentas anuales de la cofradía, aunque con ciertas lagunas para algunos años. Para cada año se apuntaban los ingresos y gastos que se habran producido, y gracias a ello, podemos conocer detalladamente las actividades benéficas que corrían a cargo de la cofradía. Sus principales fuentes de ingresos eran las siguientes:

-Numerosos censos perpetuos situados sobre casas, fundamentalmente en la collación de Santa María la Nueva, pero también en otros lugares de la ciudad. Asimismo, aunque en menor medida, también poselan algunas tierras y viñas en los alrededores de Cuenca, entregadas igualmente a censo perpetuo. Bastantes de las donaciones que el cabildo recibla de sus cofrades u otros laicos, realizadas frecuentemente por vía testamentaria, consistían precisamente en cierta cantidad de maravedís a percibir cada año perpetuamente sobre censos situados en casas. A cambio de ello, el cabildo se comprometía a mandar decir misas y aniversarios por los donantes en Santa María la Nueva.

-Limosna que se recogía los Domingos y jueves, Tres Pascuas, Todos los Santos y otros días extraordinarios. El Domingo siempre solía ser el día que más se cogía. Las cantidades globales recogidas en todos los 
Domingos del año oscilan entre los 2.000-3.000 maravedís que, como promedio, se obtenían a mediados del siglo XV, y los 6.000-7.000 que se lograban recaudar a fines de dicha centuria. La cantidad obtenida los jueves era dos o tres veces menor que la del Domingo.

-Los ingresos totales de cada año, sumando censos y limosnas, oscilan entre los $5.759 \mathrm{mrs}$ que se obtuvieron en 1440, y los $12.554 \mathrm{mrs}$ de 1467 y los 19.199 mrs que se ingresaron en 1497.

La cofradía distribura estas cantidades obtenidas anualmente del siguiente modo:

Cada Domingo se repartía una cantidad fija (entre 50 y $100 \mathrm{mrs}$ por Domingo, según los años) destinada a los pobres "envergonçantes". También habra repartos todos los años para las Tres Pascuas.

-Otra cantidad se destinaba a los forasteros pobres que pasaran por Cuenca. Durante la segunda mitad del siglo XV, la cantidad global destinada cada año a este fin oscila entre los 800 y los $2.000 \mathrm{mrs}$.

-Otra parte importante era para el mantenimiento y reparo del hospital anejo a la cofradía, el cual estaba destinado a la atención de enfermos pobres.

-En ocasiones, las cuentas del cabildo mencionan ayudas "extraordinarias" a algunas personas: cierta mujer viuda, un hombre ciego, algún cofrade que se encuentra en situación apurada, etc.

-De manera esporádica se hace mención a repartos de ropa para algunos pobres "envergonçantes"17.

La cofradía de San Francisco, San Pedro y San Pablo siempre mantuvo una estrecha vinculación con el monasterio de San Francisco de Cuenca, que se encontraba situado extramuros de la ciudad, y al cual ayudaban con frecuentes limosnas y donaciones. Entre estas últimas cabe destacar una que tuvo lugar en el año 1499, a través de la cual el cabildo entrego al monasterio un cementerio que tenían cerca de la albufera, y en el cual habia enterrados bastantes cofrades, para que pudiesen transformarlo en una huerta cultivable que les ayudara a cubrir sus necesidades, aunque previamente se deberian trasladar al claustro del monasterio los huesos de los finados, haciendo procesión y oficio solemne por ellos. Fruto de esta importante donación será la realización de una concordia de hermandad entre

${ }^{17}$ Archivo Diocesano de Cuenca, Parroquias, $n^{0} 215$. Se trata del primer libro de cuentas del cabildo y hospital de San Francisco, San Pedro y San Pablo (1436-1540), y compronde un total de 247 folios, de los cuales los primeros están muy deteriorados. 
el cabildo y el monasterio, que tuvo lugar el 8 de agosto de 1499, y a través de la cual el cabildo tendría derecho a disfrutar de muchos de los privilegios de la Orden franciscana ${ }^{18}$.

El cabildo y hospital de San Francisco, San Pedro y San Pablo pronto recibirlan una decidida protección regia. Asl, el 7 de diciembre de 1477, Isabel y Fernando se diriglan al corregidor y justicias de Cuenca mandándoles que respeten cierta costumbre antigua del cabildo por la cual su prior se encargaba de juzgar en los pleitos surgidos entre miembros del propio cabildo, asunto en el que pretendian involucrarse el corregidor y justicia local. Además, también confirmarán todas las costumbres antiguas del cabildo y hospital ${ }^{19}$. El 14 de septiembre de 1500, los mismos monarcas harán una suplicación al papa para que conceda una indulgencia plenaria a todos los que mueran en el hospital, solicitando poco después el cabildo que dicha indulgencia también sea para todos sus cofrades ${ }^{20}$. Igualmente, en el año 1500, los Reyes Católicos mandarán que no se confisquen ciertas casas donde el cabildo tenía censos que le pertenecían ${ }^{21}$.

Por lo que respecta al hospital de San Jorge, tenemos ciertas noticias acerca de su fundación. El 3 de abril de 1418, Fray Juan de Sibuet, comendador del convento-hospital de San Antón de Cuenca, otorgo licencia al cabildo y prior de San Jorge para fundar unas casas de hospital entre los de San Lázaro y San Antón, cediendo al mismo tiempo para la manutención de los enfermos pobres todo el pan que en Cuenca se recogiese con la campanilla y obligándose a dar el pan y alimento necesario para la manutención de la persona que administrase dicho hospital, además de entregar $1500 \mathrm{mrs}$ para su construcción. Poco después se otorgarfan indulgencias y perdones a todas aquellas personas que contribuyesen con sus limosnas al mantenimiento del centro 22 .

El hospital de San Lázaro ya aparece documentado en el siglo XIV en algunos testamentos, y en lo que atañe al hospital de San Sebastián, sabemos que su fundador fue el obispo de Cuenca Fray Lope de Barrientos.

\footnotetext{
18 Archivo Diocesano de Cuenca, Parroquias, no 216, ff. 293 r.-294 v.

19 Bbidem, f. 286 r.-v.

${ }^{20}$ lbidem, f. 272 r.

${ }^{21}$ Ibidem, ff. 278 r. -279 r.

22 C. SANZ y DIAZ, Historia documentada de Nuestra Sentora de la Luz, Cuenca, 1989, p.
} 41. (Archivo Municipal de Cuenca, leg. 1262, exp. 9, nota $n^{\circ} 3$ ). 
Por lo que respecta al hospital de Santa Lucia, tenemos noticias de que dependía de la cofradía del mismo nombre, la cual ya aparece documentada a fines del siglo XIV, aunque quizá su existencia venga de tiempo atrás ${ }^{23}$.

En lo tocante al hospital de Santa Quiteria, carecemos de datos sobre el mismo que nos permitan precisar con exactitud el momento concreto de su fundación, la cual tuvo que haber tenido lugar en el transcurso de las dos últimas centurias del Medievo o durante los comienzos del Antiguo Régimen.

Todos estos hospitales eran centros muy modestos, y su funcion primordial era de carácter caritativo-asistencial, pues consistía en la atención a los enfermos pobres, procedentes de los estratos más bajos de la sociedad.

Una especialización más concreta es la que posera el hospital de Todos los Santos, que se encontraba contiguo a la parroquia de San Salvador. Su finalidad esencial era la de atender a peregrinos y viajeros de paso. De su capilla era titular Nuestra Señora de la Esperanza, y aunque se ignora la fecha exacta de su fundación, la tradición le atribuye una gran antiguedad $^{24}$. No obstante, sobre la gran antiguedad de este centro, aún sin negarla, conviene señalar que hasta el momento carecemos de datos documentales fehacientes que la corroboren. Los primeros censos a favor de este hospital que han llegado hasta nosotros datan ya de mediados del siglo XVI, momento en el que sabemos que algunas del sus rentas se hallaban al parecer situadas en unas casas de la plazuela de San Andrés, en la misma ciudad de Cuenca ${ }^{25}$.

La Iglesia de Cuenca jugaria un singular papel dentro de esta corriente asistencial hacia el marginado, en la cual el "Arca de la Limosna", institución dependiente del cabildo catedralicio de la que más adelante se hablará, adquirirá un protagonismo indiscutible. Además, hacia mediados del siglo XV también se fundaŕa un hospital para acogida de pobres, cuya

\footnotetext{
${ }^{23}$ Se trata de un documento del año 1396 por el cual el cabildo de clérigos beneficiados de Cuenca entrega a censo perpetuo un molino batán a un vecino de Cuenca. De fonna casual se alude a ciertas casas de la "cofadria de Santa Locia" (AHPC, Desamortización, leg. 104, no 573).

${ }^{24}$ T. MUÑoz Y SOUVA, Op. cit. p.111.

${ }^{25}$ Archivo Histórico Provincial de Cuenca (en adelante AHPC), sección de Desamortización, leg. 508.
} 
administración correrfa a cargo de la iglesia catedral de Cuenca. Efectivamente, el 22 de diciembre de 1447, el obispo Fray Lope de Barrientos y el cabildo catedralicio decidieron destinar para hospital las casas donde solfa vivir el ya fallecido don Ruy Bernal, arcediano de Alarcon, las cuales se encontraban situadas detrás de los palacios episcopales. El nuevo centro recibirfa el nombre de Hospital de Nuestra Señora Santa Marf́a de la Consolación, y además se determina unir dicho hospital al Arca de la Limosna, de manera que ambos fuesen administrados conjuntamente por el cabildo catedralicio:

...et por ende nos don Lope de Barrientos, por la graçia de Dios e de la santa eglesia de Roma obispo de Cuenca, confesor del Rey nuestro sennor et del su consejo, oydor de la su audiençia, considerando que avemos de dar cuenta a Dios de los muchos benefiçios que nos ha dado en esta presente vida et queriendolos expender en obras de caridad, deliberamos una con el nuestro dean e cabillo de la dicha nuestra eglesia Cathedral de faser hun hospital para resçebir los pobres, adonde se podran con el ayuda de nuestro Sennor Dios conplir todas las siete obras de misericordia corporales, et por tanto statuinnos et deputamos las casas en que solia morar don Ruy Bernal, arçediano de Alarcon que Dios aya, que estan açerca del postigo detras de nuestros palaçios, para hospital, las quales nos el dicho dean e cabillo damos e ofresemos con autoridad e liçençia del dicho nuestro Sennor el obispo, la qual autoridad nos el dicho obispo interpusiemos e interponemos para faser hospital de las dichas casas. Et nos el dicho dean e cabillo resibiemos para en satisfaçion dellas otras casas que estan a renta destas, que fueron del thesorero don Martin Lopes de Fines, thesorero que fue de la dicha eglesia, que Dios aya, que nos mando dar el dicho nuestro Sennor obispo, et anexamos et unimos el dicho hospital a la helemosina de la dicha nuestra eglesia, et queremos que se llame hospital de Nuestra Sennora Santa Maria de la Consolaçion, et ordenamos que sea en el dicho hospital una capellania instituyda honor e reverençia de nuestra Sennora Santa Maria, la qual dexo Felipe Martines, defunto que dios aya, canonigo que fue de la dicha nuestra eglesia, la qual anexamos con todos sus anexos a el dicho hospital ${ }^{26}$.

Poco tiempo después de su fundación ya nos encontramos con las primeras donaciones hechas a favor de este hospital. Un ejemplo de ello lo tenemos en la manda piadosa que hizo en 1450 el chantre don Nuño Álvarez de Fuentencalada:

${ }^{26}$ ACC, Actas Capitulares, A-5, año 1447, ff. 20 v-21 r. 
Item, dio el dicho chantre a la Elimosna et Ospital de la dicha Eglesia una casa de heredat en Embit...27.

Otro aspecto de interés lo constituye la actitud asistencial hacia niños huérfanos o abandonados. Durante el transcurso de los últimos siglos del Medievo en todo Occidente la suerte de los huérfanos y de los niños abandonados fue objeto de un cuidado acrecentado. Fundamentalmente a partir del siglo XIV unos hospitales especiales destinados a ellos comenzaron a fundarse. De este modo el abanico de las necesidades hospitalarias se beneficiaba, en su conjunto, de una cierta tendencia a la especialización ${ }^{28}$.

La existencia en Cuenca de un hospital de estas características aparece documentada en 1488. El 21 de marzo de este año el cabildo catedralicio acordará ceder a Alonso Ruiz, canónigo, unas casas que eran llamadas "de las Beatas", para que instale en ellas un hospital destinado a recibir niños "expósitos" que eran abandonados a la puerta de la iglesia sin bautizar:

...Los dichos sennores dean e cabildo fizieron concesion de las dichas casas al dicho Alonso Ruiz para que fiziese et hedificase en ellas un ospital para criar los niños que fueren echados a la puerta de la yglesia por bautizar, y halas de doctar con ciertas condiciones...e asy mesmo que pueda en la dicha casa poner personas de honesta vida que tengan cargo de resçebir las dichas criaturas e darlas a criar syn demandar cosa alguna a los dichos sennores dean e cabildo... ${ }^{29}$.

Asl, pues, vemos cómo en este caso aparecen implicados tanto el colectivo capitular, que cede el edificio donde se instalará el hospital, como

${ }^{27}$ ACC, Necrologio-Obituario, f. 45 r.

28 Los llamados "niños expósitos" son sujetos que tradicionalmente se han considerado pobres en el sentido de que son desvalidos. En Castilla contamos con varios ejemplos al respecto. Uno de ellos es la fundación aneja a la catedral de Salamanca que atendía a estos niños expósitos, los cuales solían ser abandonados a la puerta de la catedral, según una costumbre que se encuentra también documentada en otros lugares. Otros centros fundados exclusivamente para los niños abandonados eran el hospital de Santo Tomé de Astorga, documentado ya en el siglo XIV, o la "Capellanía de los enechados" de Zamora (C. LOPEZ ALONSO, La pobreza en la España Medieval, p. 418).

${ }^{29}$ Archivo Histórico Nacional, sección de Microfilmes, rollo 14232. El cabildo pondrá como condición de la donación de las casas que Alonso Ruiz y otras personas que quieran doten anualmente con $2.0000 \mathrm{mrs}$. de renta dichas casas por espacio de diez años, para que con ello se mantenga el cuidado hacia los niños expósitos. En caso de que esto no se cumpliese, dichas cases volverían a poder del cabildo y se mantendrían a costa de las rentas del Arca de la Limosna. 
una persona particular, en concreto un canónigo, a cuyo cargo correrá la dotación y el mantenimiento del hospital, tarea en la cual podría ser auxiliado por otros fieles que asi lo deseasen. Por lo tanto vemos cómo en ocasiones la actitud asistencial hacia el pobre dependía tanto de iniciativas colectivas como de otras con carácter particular.

Como ejemplo de estas últimas también destacan las llevadas a cabo por ciertos prelados. Asi, el 1 de febrero de 1335, el obispo de Evora don Pedro Martínez, que con anterioridad habla sido deán de la catedral de Cuenca, mandará a Lopálvarez, su criado y canónigo de Cuenca, que recoja todos los bienes que tenia alli, pues quería destinarlos a un hospital que habia mandado hacer en esta ciudad para el bien de su alma ${ }^{30}$. Por otro lado ya se indicó líneas atrás cómo el obispo de Cuenca Fray Lope de Barrientos (1445-1469) creó en Cuenca el hospital de San Sebastián, aunque su fundación más importante fue la del hospital de San Antonio de Medina del Campo, donde serfa enterrado ${ }^{31}$.

\section{Los hospitales rurales. La casa-hospital de Fuentes}

Este desarrollo de los hospitales al cual se viene aludiendo no será, ni mucho menos, exclusivo de la ciudad de Cuenca. También en diversos centros rurales de la diócesis se fundarán hospitales con un marcado carácter caritativo-asistencial, respondiendo con frecuencia su creación a iniciativas de carácter particular.

Un ejemplo de esto último que se acaba de señalar lo tenemos en el hospital de San Andrés que hacia principios del siglo XV fundó don Juan Fernández Pacheco en su villa de Belmonte, dotándolo muy bién para poder curar y atender a enfermos pobres y hospedar peregrinos, asi como para proveer de lo necesario a algunos de sus escuderos que hubiesen venido a menos y poder sustentar a un capellán que dijese misa a los enfermos. Esta dote y limosna inicial sería aumentada posteriormente por su nieto el maestre de Santiago don Juan Pacheco, marqués de Villena ${ }^{32}$.

\footnotetext{
${ }^{30}$ ACC, siglo XIV, $n^{0}$ 57. La constatación de que este prelado había sido con anterioridad deán de la catedral de Cuenca se encuentra recogida en ACC, Actas Capitulares del año 1329 (cuademillo aparte), A-1, f.1.

${ }^{31}$ L. ALONSO Getino, Vida y obras de Fray Lope de Barrientos, "Anales salmantinos", I (Salamanca, 1927), p. LXXII.

${ }^{32}$ L. ANDÚjAR ORTEGA, Belmonte, cuna de Fray Luis de León. Su Colegiata, Cuenca,
} 
También dentro de este contexto de la asistencia al pobre a través de iniciativas de carácter particular destacan ciertas fundaciones hospitalarias que quedarán plasmadas en el contenido de algunos testamentos ${ }^{33}$. Un claro exponente al respecto, para el caso conquense, lo constituye el testamento de Juan Martínez de Medina, canónigo de Cuenca, datado el 24 de septiembre de 1377. A través de él mandará, entre otras muchas cosas, que las casas que habra mandado edificar en la aldea de Fuentes para desempeñar la función de hospital sigan cumpliendo dicha función y acogiendo a los pobres para darles lecho y alimento. También mandará que el abad del cabildo de clérigos de Cuenca, junto con un clérigo de Fuentes y dos hombres buenos del concejo de dicha aldea, pongan para que se encargue del mantenimiento de dicho hospital a un hombre de confianza, el cual les tendrá que dar cuenta cada año acerca de la marcha de la casa. Es significativo que también se añada:

Et non es mi voluntad que del dicho hospital nin de sus bienes pueda ordenar obispo nin otro sennor alguno, si non los sobredichos abad e clerigo e omes buenos...

Ello puede ser interpretado como un indicio de la desconfianza que en ocasiones se daba por parte de algunos eclesiásticos hacia los prelados, verdaderos señores que a veces podían hacer un uso indebido de las rentas eclesiásticas en el sentido de obtener de ellas beneficios personales.

Finalmente se determinará que Mateo Gil se haga cargo de la mencionada casa-hospital, siempre bajo la supervisión del abad, clérigo y hombres buenos sobredichos, los cuales, a su muerte, nombrarán otro encargado que nunca deberá disipar los bienes y propiedades del hospital.

En el testamento también se especifica que el día de su entierro se dé a diez pobres de comer, lo cual, junto a una probable finalidad caritati-

1985, pp. $39-40$.

${ }^{33}$ Ello es algo que se dará tanto en testamentos de eclesiásticos como de laicos, y pueden encontrarse ejemplos de ello para toda la Corona de Castilla. En este contexto se sitúa, por citar un caso significativo, la fundación del hospital de Santa María la Real de Burgoa; en 1337 Elvira González, perteneciente a una familia vinculada al comercio, otorga su testamento, que es abierto y publicado con autoridad judicial el 6 de marzo de 1341 y por el que funda y declara heredero universal de sus bienes al hospital de Santa Maria la Real (L. MARTINEZ GARCfA, La asistencia a los pobres en Burgos en la Baja Edad Media, p. 37). 
va, también tenía el indudable objetivo de realzar el prestigio social del testado ${ }^{34}$. Volviendo al hospital de Fuentes, en 1396 el arcediano de Cuenca Andrés Fernández aparece como administrador del mismo. Este personaje, el 23 de febrero de dicho año, otorgará en calidad de censo enfitéutico a Nicolás Sánchez una dehesa con casa que llaman "Gallesoga", en término de la ciudad de Cuenca, bienes que pertenecian al hospital de Fuentes. A cambio de ello Nicolás Sánchez se compromete a hacer ciertas reparaciones en la casa y a pagar todos los años de censo 25 florines de oro del cuño de Aragón ${ }^{35}$. Ello nos está indicando que el sistema empleado para poner en explotación los bienes de este modesto hospital consistía en su entrega en calidad de censo enfitéutico, procedimiento mediante el cual los censatarios se obligaban a entregar a perpetuidad todos los años una renta fija al arrendador. De este modo se aplicará al hospital un sistema de explotación indirecta muy frecuentemente utilizado por la Iglesia. Para el hospital este procedimiento ofrecía sin duda ciertas ventajas: comodidad en la explotación de sus bienes y la garantía de percibir una renta fija todos los años; no obstante, dado el carácter hereditario del contrato, se podfa correr el riesgo de que a la larga se produjese un cierto estancamiento en la cantidad a percibir todos los años en calidad de censo.

En 1401 se presentarán quejas de que algunas tierras pertenecientes a los bienes del hospital de Fuentes estaban encubiertas, debido a lo cual intervendrá un canónigo de Cuenca para hacer inventario de los bienes raices de la heredad aneja al hospital, y de este modo intentar que el centro asistencial percibiese integros todos sus derechos. El 14 de marzo del mismo año Miguel Ferrández, tesorero de la Iglesia de Cuenca y administrador del hospital, mandará hacer un inventario de todos los bienes muebles que all habra, el cual resulta muy ilustrativo acerca de la extremada modestia que caracterizaba a este centro asistencial:

\footnotetext{
${ }^{34}$ El testamento de Juan Martínez de Medina en AHPC, sección de Varios, n⿳ 5 . El dejar encargado que se dé de comer o se entreguen ropas a cierto número de pobres en lo entierros era una práctica bastante difundida entre las altas capas de la sociedad, y en el caso de Cuenca la encontramos también documentada en otras ocasiones. Así, por ejemplo, en 1329 María Sánchez, hija de Pedro Sánchez de Montesinos, mandará en su testamento, entre otras cosas, "que vistan veynte pobres, los dos[e] de sayal e los otros dies de lienço..." (ACC, siglo XIV, n 206), y en 1439 Martín González, canónigo de Cuenca, dejará encargado en su testamento que al día siguiente de su entierro den de comer a doce pobres (AHPC, sección de Varios, $n^{\circ}$ 8-A).
}

35 AHPC, sección de Varios, no 3-A. 
-En una casa pequeña: una cama tablada; un almadraque de lienzo gordo; una lechera listada comunal; una manta de paño; dos cabezales; varias cabeceras de lienzo; una pala de hierro y tres rejas; dos tajadores y tres escudillas.

-En otra casa pequeña, al lado de la anterior: una cama tablada nueva, un almadraque y varios cabezales, entre otras cosas.

-En la casa donde está la cocina: un lechón viejo, un arca vieja y un par de sábanas, además de otros utensilios.

Una vez hecho el mencionado inventario de los bienes muebles, éstos quedaron en poder de Ferrant Sánchez, vecino de Fuentes que desempeñaba la función de casero del hospital ${ }^{36}$.

Tenemos noticia de que hacia mediados del siglo XV el hospital se vio envuelto en una serie de conflictos con ciertos vecinos de Fuentes y de otros lugares cercanos. En 1443 encontramos a Juan Alfonso de Oña, abad de Santiago (dignidad del cabildo catedralicio conquense), como administrador de la casa-hospital de Fuentes. Se quejará de que algunos vecinos de Fuentes y otros lugares cercanos entraban en una dehesa perteneciente al hospital en el lugar de Gallensoga, en la cual el ganado mayor y menor pastaba ilegalmente y donde dichos vecinos cortaban madera de pino y carrasca sin permiso del hospital. De este modo, el 29 de enero del mencionado año, don Martín López de Bólliga, alcalde entregador de las Mestas y cañadas de Cuenca, confirmará al hospital un privilegio por el que se pro-

${ }^{36}$ AHPC, sección de Varios, no 5 . Así, pues, de la lectura del inventario se deduce que apenas tres lechos eran los que poseía esta modestísima institución asistencial. El hecho de que hubiese numerosos hospitales en la Castilla bajomedieval no nos debe confundir a la hora de pensar en su eficacia. Junto al aspecto cuantitutivo debe de tenerse en cuenta también el cualitativo. A diferencia de los creados en épocas anteriores, bajo los auspicios del rey o del obispo, muchos hospitales fundados en los siglos XIV y XV fueron, en líneas generales, bastante modestos. Así, el hospital de Nuestra Señora de la Misericordia de Salamanca, fundado en 1389, disponía de 6 lechos; el hospital de San Juan Bautista de Castromocho (Palencia) tenía 12 lechos. En cambio, el hospital de San Antolín de Palencia, fundado por el capellán del obispo a mediados del siglo XII y ampliamente dotado por el rey Alfonso VIII poco después, disponía en el siglo XVI de 88 camas. Según M. Mollat podría cstablecerse una media general para Europa entre 25 y 30 camas por hospital, aunque, como él mismo señala, los de la Península Ibérica fueron, salvo en algunos casos, inucho más modestos. No pocos debieron ser los que se ajustaron a la cifra de 12 o 13 lechos, tal como establecía el "mandatum" evangélico, en recuerdo del colegio apostólico. Bastaba, en fin, con que una institución tuviera 2 ó 3 camas par ser considerada hospital (L. MARI1NEZ GARClA, La asistencia a los pobres en Burgos, p. 27). 
híbe a dichos vecinos de Fuentes y lugares cercanos que metan sus ganados en la dehesa del hospital, asi como que corten alli madera ${ }^{37}$.

En definitiva, el hospital de Fuentes se nos presenta como un centro asistencial extremadamente modesto, con apenas tres lechos y un discretísimo inmobiliario, cuya administración corría con frecuencia a cargo de algún miembro del cabildo catedralicio conquense y cuyo fin primordial era la atención a enfermos pobres, tal como dejó indicado el fundador en su testamento, lo cual era posible gracias a los ingresos obtenidos mediante la explotacion indirecta de los bienes rafces que eran propiedad de la casahospital.

\section{La iniciativa concejil}

Toda esta corriente institucionalizadora de la asistencia al pobre no estuvo exclusivamente protagonizada por la Iglesia, aunque será ésta, al menos en el caso de Cuenca, la que desempeñe un papel más sobresaliente. El concejo de Cuenca también cumplirá una importante función en todo este proceso.

Durante la Baja Edad Media, a diferencia de los siglos anteriores, en los que la Iglesia habła monopolizado por completo la actividad benefica, destaca el creciente papel de los laicos al respecto. Ahora, cuando el pobre y el vagabundo se consideran peligrosos para el orden social institurdo, las autoridades laicas intervendrán activamente junto a los poderes eclesiásticos. Sobresale en este punto el papel ejercido por las cofradías y el progresivo intervencionismo de-los poderes municipales e, incluso, de los monarcas.

Un ejemplo significativo de este intervencionismo por parte del concejo de Cuenca lo tenemos en la instauración de la figura del "abogado de los pobres" en el municipio conquense a raíz de la reforma municipal de Fernando de Antequera del año 1411. Este personaje era nombrado y remunerado por el propio concejo para atender los problemas relativos a la pobreza y marginación en la ciudad ${ }^{38}$.

\footnotetext{
${ }^{37}$ AHPC, sección de Varios, n' 10-A.
}

${ }^{38} \mathrm{M}^{*}$ D. CABANAS GONZÁlEZ, La reforma municipal de Femando de Antequera en Cuenca, "Anuario de Estudios Medievales", 12 (1982), p. 384. 
El concejo de Cuenca también contribuirá al mantenimiento de algunos centros hospitalarios de la ciudad. Asf, el 23 de marzo de 1514, a petición de Antón de Serraza, mayordomo de la casa-hospital de San Lázaro, el concejo concederá a dicha institución "lo que los moros tenian por honsario [cementerio] y no mas, que es muy poca cosa y no perjudica a la ciudad" $^{39}$.

\section{EL ARCA DE LA LIMOSNA}

\section{La caridad del clero y los laicos}

Sin duda la institución asistencial hacia los pobres de mayor relieve que hubo en Cuenca a fines del Medievo y durante los siglos del Antiguo Régimen fue la llamada "Arca de la Limosna". Tradicionalmente se ha considerado que su creación tuvo lugar en el año 1403, siendo su fundador el obispo don Juan Cabeza de Vaca (1397-1406); así lo señalaron en el siglo pasado autores como Mateo López o Trifon Muñoz y Soliva, y este dato también será recogido por la historiograffa posterior. No obstante, en el libro de Pitancería del año 1400 , que es el primero de la larga serie que se conserva en el Archivo de la catedral de Cuenca, ya se alude a lo que "monta" la limosna (en maravedíes) cada mes, recogiéndose también la cifra total correspondiente a la limosna para todo el conjunto del año ${ }^{40}$. Sin duda con ello el documento nos está informando de que el "Arca de la Limosna" ya existía en esta fecha, por lo que, de haber sido don Juan Cabeza de Vaca su fundador, tuvo que haber sido entre los años 1397(año en que comienza el pontificado de este prelado en Cuenca) y 1399 cuando se creo el Arca de la Limosna, aunque el documento fundacional no ha llegado hasta nosotros.

El Arca estaba en gran medida vinculada al cabildo catedralicio de Cuenca, y pronto encontraremos a la figura del "limosnero" (que casi siempre era un canonigo, racionero o dignidad catedralicia) encargándose de la administración de las rentas y patrimonio de esta importante institución

${ }^{30}$ M. GARCta ARENAL, La aljama de los moros de Cuenca en el siglo XV, "Historia, Instituciones, Documentos", 4 (1977), p. 47.

${ }^{40}$ ACC, Pitancería, año 1400, f. 177 v. 
benéfica de índole eclesiástica. Conviene resaltar el hecho de que dicho patrimonio, compuesto primordialmente por bienes rarces, se formo y enriqueció básicamente a partir de donaciones realizadas por eclesiásticos, y en particular por miembros del cabildo catedralicio, aunque tampoco faltarán las donaciones de laicos ${ }^{41}$.

En efecto, el Derecho Canónico establece la obligación que todos los cristianos tienen de atender a los pobres mediante la limosna pero, tal como ya se indica en las Partidas, son en primer lugar el alto clero y los prelados quienes deben atender a los pobres que a ellos acudan, sobre todo si son pobres vergonzantes. En general la mentalidad de la época considera que son aquellas personas que ocupan los puestos más elevados en la sociedad quienes están particularmente obligados a la limosna, dado que la riqueza cumple una determinada función en tanto que compensadora de la pobreza ${ }^{42}$.

Tal como se acaba de señalar líneas arriba, el "Arca de la Limosna" de la catedral de Cuenca recibiría importantes donaciones por parte de algunos miembros del cabildo catedralicio. Son varios los testimonios documentales que sobre esto han llegado hasta nosotros. A su vez, todo ello nos ofrece bastante informacion sobre el sistema empleado en la administración del patrimonio perteneciente al Arca.

En un documento datado en Cuenca, a 10 de octubre de 1404, se nos indica cómo el canónigo Pero Moriel, ya fallecido, habra dispuesto en su testamento que sus bienes y dinero se destinaran a comprar heredades

\footnotetext{
${ }^{41}$ Estas "Arcas de Misericondia" también las encontramos en otros lugares de la Corona de Castilla, como por ejemplo en la catedral de Salamanca y en la iglesia parroquial de San Ildefonso de Zamora. Se encargaban de recoger las limosnas que los fieles quisieran depositar y que, en el caso de la catedral de Salamanca, los canónigos entregaban a los pobres, cofradías, hospitales, etc. Algo similar ocurre con los "platos" o "bací" de los pobres en las iglesias catalanas, o con las diversas limosnerías fundadas por particulares ya desde principios del siglo XIII y administradas por el cabildo catedralicio o las óndenes monásticas (J. SÁNCHEZ HERRERO, Cofradias, hospitales y beneficiencia en algunas diócesis del Valle del Duero, $p$. 44). En los monasterios que poseían limosneria solía ser siempre un monje de la comunidad quien desempeñaba el oficio de limosnero; sobre ello puede verse el breve trabajo de $\mathbf{M}$. CANTERA MONTENEgro, El oficio de la limosneria en Santa Maria la Real de Nájera. Siglos XI-XV, "En la España Medieval", 4 (1984). En 1431 fueron aprobadas por una bula de Eugenio IV las Arcas de Limosna del conde de Haro. Fueron creadas para ejercer la caridad hacia los pobres y marginados, y por ello su fundador dotará con 11.560 florines de oro las que establece en las distintas parroquias de su territorio. Vid. F. LOPEZ YEPES Y SAGREDO, Las Arcas de Limosna del conde de Haro y las instituciones de préstamo benéfico. Siglos XVXVI, "A pobreza e a assistencia aos pobres", vol. II.
}

${ }^{42}$ C. LOPEZ ALONSO, La pobreza en la España Medieval, p. 264. 
con el fin de entregar las rentas que produjesen a los pobres y al Arca de la Limosna. Pero el cabildo catedralicio determinó que serfa más provechoso destinar parte de ese dinero a reparar unos molinos de Villalba. De este modo Guillén Barral, deán de Cuenca, y Juan Rodríguez, chantre, como testamentarios del dicho Pero Moriel, darán su consentimiento al cabildo conquense para que puedan emplearse hasta $200 \sigma 300$ florines de oro del cuño de Aragón en la reparación de dichos molinos, pero con la condición de que todos los años se entregue a los pobres un tercio de la renta de los molinos y heredad de Villalba. En caso de que el cabildo devolviese el dinero prestado para dichos molinos, entonces ya se veria libre de entregar dicha tercera parte de la renta para los pobres y el Arca de la Limosna ${ }^{43}$.

En los años siguientes el cabildo invertirla el resto del dinero dejado por Pero Moriel en la compra de bienes rafces cuyas rentas irlan destinadas, al menos en teoria, al Arca de la Limosna. Asi, en 1405 Ferrant García de Tordera venderá al Arca de la Limosna una casa y corral con dos yuntas de heredad en Tordera, aldea cercana a Cuenca, por 180 florines de oro del cuño de Aragón procedentes de los que habla dejado en su testamento el canónigo Pero Moriel.

El intermediario que actuó en dicha venta en nombre del cabildo fue Juan Rodriguez, chantre-limosnero en la Iglesia de Cuenca. Dos años más tarde, en 1407, Fernán Sánchez de Teruel otorgará la mitad de una heredad, también en Tordera, que cinco años antes le habra vendido Gonzalo Garcia, en favor del limosnero Juan Rodríguez, por precio de 220 florines de oro del cuño de Aragón; las rentas que produjese la mitad de dicha heredad se destinarian, logicamente, al Arca ${ }^{44}$.

El 3 de abril de 1426 Martín González, canónigo prebendado de la Iglesia de Cuenca, hará una donación perpetua "inter vivos" de todos sus bienes a la Iglesia de Cuenca, la mitad de los cuales habria de ser para la limosna que, procedente del Arca, se entregaba todos los dias a los pobres en la catedral. La otra mitad sería para el cabildo, a cambio de tres aniversarios al año a perpetuidad, uno por su alma, y los otros dos por las de sus padres y parientes. En el documento se especifica que dichos bienes pasa-

\footnotetext{
${ }^{43}$ AHPC, sección de Varios, n 6-A.

* AHPC, sección de Desalnortización, leg. 92.
} 
rán a posesión efectiva del cabildo y Arca de la Limosna sólo una vez que Martín González haya muerto ${ }^{45}$.

No obstante, el 29 de junio de 1439 el mencionado Martín González hará un nuevo testamento revocando todos los anteriores. En éste se establecen ciertas variantes con respecto a las anteriores disposiciones. Asi, entre otras cosas, hará una pequeña donación monetaria de $50 \mathrm{mrs}$ a todas las iglesias parroquiales de Cuenca, excepto a la de San Salvador, que recibirá $250 \mathrm{mrs}$, y a cada una de las cuatro casas de San Lázaro de Cuenca, que eran modestos centros hospitalarios, entregará la cantidad simbólica de 2 mrs. Pero en esta ocasión también el cabildo catedralicio y el Arca de la Limosna seguirán siendo, con mucho, los más beneficiados, pues recibirán la donación de más de 20 casas situadas en las collaciones de Santo Domingo, San Pedro, San Andrés y en otros lugares de la ciudad, a cambio de seis aniversarios perpetuos por su alma y las de sus padres. En el testamento también se especifica que al día siguiente de su entierro se dé de comer a doce pobres, número con el que sin duda se está haciendo una alusión simbólica al colegio apostólico ${ }^{46}$.

También en una manda piadosa hecha por el chantre don Nuño Álvarez en el año 1450, y cuyo texto está contenido en el Necrologio-Obituario de la catedral conquense, se donarán ciertos bienes al Arca de la Limosna. En efecto, además de dejar varias cantidades de dinero, libros y otros bienes muebles e inmuebles al cabildo, dotará con una casa y diversas tierras al Arca de la Limosna y al hospital de la catedral, tal como señala el texto:

Item, dio el dicho chantre a la Elimosna et Ospital de la dicha Iglesia una casa de heredat en Embit, con cuatro o fasta cinco yuntas de tierras aboyadas con dos bueyes nuevos, segun se contiene en una donacion que fizo a la dicha Elimosna... 4 .

Cinco años más tarde, en 1455, don Juan Alfonso de Oña, abad de Santiago y canónigo de Cuenca, donó cuatro yuntas de heredad y varias casas en Colliguilla al Arca de la Limosna ${ }^{48}$.

\footnotetext{
4s AHPC, sección de Varios, n 8-A.

${ }^{46}$ Bbidem.

${ }^{47}$ ACC., Necrologio-Obituario, f. 45 r.

4 AHPC, sección de Desamortización, leg. 90, no 5598.
} 
Es en este contexto de ejercicio de la caridad donde debe situarse la actuación del obispo de Cuenca Fray Lope de Barrientos (1445-1469) durante los años 1468 y 1469. Ante la situación de carestía que se venía dando desde hacía varios años en Castilla, y también en la diócesis conquense, es probable que una buena parte de las rentas del obispado y reales de las que sabemos que se apodero este prelado en 1468 y 1469 fuesen invertidas en la atención a los pobres. En efecto, era costumbre de don Lope lanzar al mercado las rentas en grano del obispado con objeto de ampliar la deman$\mathrm{da}$, facilitando el abastecimiento de la población, evitando o paliando el alza de los precios, y tratando de luchar contra los efectos de la especulación y el acaparamiento. También hay que recordar que es él quien crea en Medina del Campo el hospital de San Antonio, y en la propia Cuenca el de San Sebastiann ${ }^{49}$.

Asimismo, por estos años el Arca de la Limosna recibiría un nuevo impulso a través de nuevas donaciones por parte de eclesiásticos, como la efectuada por el canónigo Lorenzana que, a su muerte, ocurrida antes de 1477 , la constituyó como su heredera universal ${ }^{50}$.

En definitiva, a través de los ejemplos recién expuestos resulta evidente que los miembros del cabildo catedralicio, sobre todo los más pudientes económicamente, jugaron un papel esencial en el enriquecimiento del patrimonio del Arca de la Limosna a través de diversas donaciones cuya importancia será variable según los casos; en unas ocasiones el donante entregará a esta institución asistencial sólo una pequeña parte de su patrimonio, mientras que otras veces nos encontramos con donantes que la constituyen su heredera universal.

Estas donaciones deben ser interpretadas en un doble sentido: por un lado debe ser destacado en ellas el aspecto de tipo caritativo-asistencial, pero por otra parte hay que poner de relieve que acciones de esta indole realzaban, indudablemente, el prestigio social del donante, pues los canónigos formaban parte de la oligarquia urbana y el ejercicio de la caridad por parte de los más pudientes hacia los pobres constitura una exigencia social que habra que tener siempre presente.

49 S. AGUADÉ NIETO, Crisis de subsistencia, rentas eclesiásticas y caridad en la Castilla de la segunda mitad del siglo XV, "En la España Medieval", 2 (1982), p. 35.

${ }^{50}$ Mateo LOPEZ, Memorias históricas de Cuenca y su obispado, Madrid, CSIC, 1949 (El manuscrito original data de fines del siglo XVIII), vol.II, p.209. 
Pero no serán sólo los eclesiásticos quienes contribuyan al enriquecimiento del patrimonio del Arca de la Limosna. Aunque en menor medida, los laicos también jugaron un importante papel en este sentido, y sobre ello conservamos varios ejemplos documentados.

El 30 de septiembre de 1433 otorgó su testamento Toda Sánchez, mujer de Fernando Ortezuela, y por una cláusula del mismo dejo al Arca de la Limosna la casa y heredad que posera en Valdecabrillas y que posteriormente el cabildo entregaria a censo enfitéutico ${ }^{51}$.

El 27 de enero de 1478 Gonzalo Sánchez de Valdemeca, vecino de Cuenca, incluirá un codicilo en su testamento a través del cual otorga a sus hijos la mitad de unas casas en la calle de Santo Domingo que eran de su propiedad, y la otra mitad al Arca de la Limosna de la catedral de Cuenca, para el bien de su alma y la de su segunda mujer. Dejará encargado que, dado que estaban alquiladas, la renta que produzca la parte de dichas casas correspondiente al Arca de la Limosna se invierta en una fanega de trigo para ayuda de los pobres que habrá de entregarse perpetuamente cada año al limosnero en el día de Santa María de agosto ${ }^{52}$.

En algunos testamentos pertenecientes a la nobleza que ocupaba el territorio de la diócesis de Cuenca también encontraremos alguna cláusula a través de la que se hacen ciertas donaciones destinadas a paliar las necesidades de los pobres. Un ejemplo de ello lo constituye el testamento de Pedro Ruiz de Alarcón, señor de Valverde, redactado en 1485, en el que figuran, entre otras mandas, una de 2400 mrs destinada a resarcir el despojo que habla causado a los judfos de Almazán durante la guerra civil de 1464 a 1468; otra de 150000 mrs con vistas a la redención de cautivos y, finalmente, una tercera de 1386 mrs destinada a "personas pobres que lo hayan menester, quales mis testamentarios nombraren...", aunque en este caso no se hace ninguna alusión especifica al Arca de la Limosna ${ }^{53}$.

Pocos años después, en 1489, hará testamento Teresa Fernández, vecina de Cuenca. Entre sus cláusulas figura una por la que deja al Arca de la Limosna ciertas casas que eran de su propiedad y que se encontraban situadas en la calle de los pescadores. También mandará a su sobrino el bachiller Sancho de la Torre que se encargue de que digan perpetuamente

\footnotetext{
${ }^{51}$ AHPC, sección de Desamortización, leg. 90, no 5598.

32 AHPC, sección de Desanortización, leg. 92.

${ }^{33}$ S. Aguadé Nieto, Crisis de subsistencia, p.37.
} 
cada semana, los miércoles y viernes, dos misas por su alma y por las almas de Diego de Cañete y de Bartolomé García, su marido, y establece que las diga un clérigo seglar en el monasterio de San Francisco de Cuenca. También encargará a su sobrino, como patrono de la capellanía que se va a fundar en este monasterio, que se ocupe de que se ponga cera para el día de Todos los Santos y durante el día en que se hace conmemoración de los Difuntos. Asimismo, manda que se compre una heredad por precio de 30000 mrs para con sus rentas hacer frente al coste de dichas misas, y que el patronazgo de dicha capellania siempre lo tenga un miembro de su familia, el cual se encargará de decir dichas misas, si fuera sacerdote, o de mandar decirlas a otros. Se establece que la administracion de dicha heredad la tenga siempre un descendiente de su linaje, pero que nunca se inmiscuya ningún arzobispo, obispo ni legado pontificio. Para el patronazgo de la capellania manda que se entreguen unas casas que tiene en la calle de los caballeros. Finalmente se indica que, pasada la cuarta generación desde su sobrino, dicha heredad y casas pasen a formar parte del patrimonio del Arca de la Limosna con cargo de las dos misas cada semana en San Francisco $^{54}$.

En definitiva, a través de los ejemplos recién expuestos puede apreciarse cómo, aunque fueron los eclesiásticos quienes más donaciones hicieron al Arca de la Limosna, en ocasiones los laicos también jugaron un papel importante en este sentido.

\section{La administración del patrimonio del Arca de la Limosna}

La documentación que ha llegado a nosotros sobre esta cuestion, aún no siendo muy abundante, sí es lo suficientemente variada como para permitir que nos podamos hacer una idea bastante aproximada acerca de los bienes patrimoniales pertenecientes al Arca de la Limosna, asf como sobre la administracion de los mismos.

En primer lugar, en función de la documentación disponible, haremos un breve repaso a algunas de las principales pertenencias del Arca de la Limosna en ciertos lugares de la diocesis, indicando el valor de las mismas, los apeos e inventarios que se realizaron y el sistema de explotación utilizado que, tal como a continuación se comprobará, fue siempre una

34 AHPC, sección de Desamortización, leg. 90, nº 639. 
explotación indirecta mediante la entrega de las tierras a censo, predominantemente de carácter perpetuo. Seguidamente, tras exponer todo esto, extraeremos unas conclusiones básicas sobre el patrimonio del Arca de la Limosna, su administración y forma de explotación.

-Arcas

El 23 de febrero de 1473, estando reunidos el deán y cabildo conquenses, comparecio ante ellos Pedro Fernández, vecino de La Melgosa, al cual cedieron en calidad de censo enfitéutico una heredad en Arcas que anteriormente habra donado al Arca de la Limosna Francisco Bordallo, abad de la Sey. El censo será de 32 almudes de trigo de la medida menor, pagaderos todos los años para el día de Santa María de agostoss.

\section{-Cólliga}

En 1454 Isabel Sánchez habia donado al Arca de la Limosna una heredad en Cólliga. Se trataba de dos yuntas de heredad que pocos años después de pasar a engrosar el patrimonio del Arca dejarían de labrarse y visitarse por parte del cabildo catedralicio, con lo cual algunos campesinos de lugares proximos acabaron apropiándose de estas tierras y labrándolas sin permiso del cabildo. Debido a ello, en el año 1500 el cabildo optaría por entregar estas dos yuntas de heredad, en calidad de censo perpetuo, a Francisco y Miguel Bordallo, vecinos de Cólliga, los cuales tendrían que pagar todos los años 30 almudes de trigo de la medida mayor al Arca de la Limosna, y la primera paga comenzarfa el día de Santa María de agosto de $1501^{36}$.

\section{-Colliguilla}

El 22 de mayo de 1436 se hará un apeo, deslinde y amojonamiento de una heredad que posela el Arca de la Limosna en Colliguilla. Tras realizarse el apeo se comprobo que la heredad constaba de 2799 almudadas de

\footnotetext{
ss AHPC, sección de Desamortización, leg. 601, no 1119.

so Ibidem, leg. 687.
} 
siembra, aunque en otro apeo hecho por las mismas fechas figura que son 3029 almudadas.

En 1486 se harfa un nuevo apeo e inventario de dicha heredad y de unas casas que también posera el Arca en Colliguilla, dado que el cabildo catedralicio se habra enterado de que algunos campesinos de las zonas proximas habfan entrado y ocupado las tierras de dicha heredad (tanto cereal como huerta) pertenecientes a la Limosna ${ }^{57}$.

\section{-Cuenca}

En la ciudad de Cuenca el Arca de la Limosna posera un importante número de bienes inmuebles, fundamentalmente casas. En este aspecto conviene recordar cómo el 29 de junio de 1439 el canónigo Martín González habra hecho un nuevo testamento, donando al cabildo y al Arca de la Limosna más de 20 casas situadas en los barrios de Santo Domingo, San Pedro y San Andrés ${ }^{58}$.

Todas estas casas se explotaban de forma indirecta, entregándolas a censo. AsI, por ejemplo, en 1452 tenemos noticia de un censo de dos florines de oro al año a pagar sobre unas casas en la Puerta Ferrada, pertenecientes al Arca, siendo Francisco López de Sacedón canónigo-limosnero. En 1472 el cabildo entregará, en calidad de censo enfitéutico, a Francisco de Cuenca, sastre, unas casas en la collación de Santo Domingo, que eran de las que donó al Arca de la Limosna el canónigo Martín González. El acuerdo se hace siendo Luis Garcia racionero-limosnero, y en él se establece que Francisco de Cuenca habría de pagar todos los años al cabildo 140 mrs de censo sobre dichas casas, cantidad que irfa destinada integramente al Arca. En 1483 nos encontramos con un nuevo censo de dos florines de oro anuales para el Arca de la Limosna, situado sobre unas casas en la Zapatería, y en 1492 tenemos constancia de un censo perpetuo de $200 \mathrm{mrs}$ anuales sobre unas casas en la plazuela de San Andrés, que pagaban Fernando de la Rambla y su mujer al Arca de la Limosna ${ }^{\text {so. }}$.

\footnotetext{
57 Ibidem.

38 AHPC, sección de Varios, documento 8-A.

s9 AHPC, sección de Desamortización, leg. 92.
} 
-Ribagorda

En 1447 hizo testamento Juan Sánchez de Palacios, vecino de Cuenca, y a través de una cláusula del mismo donó al cabildo catedralicio de Cuenca y al Arca de la Limosna, a partes iguales, una casa y heredad en Ribagorda, con cargo de un aniversario perpetuo ${ }^{60}$.

El 5 de mayo de 1448 se entrego esta heredad en calidad de censo enfitéutico a unos moradores de Ribagorda, y al día siguiente, estando presentes diversos testigos (vecinos de Ribagorda y Ribatajada), Francisco López de Sacedón (canónigo-limosnero) y otro canónigo de Cuenca, se procedió a hacer un inventario y apeo de los bienes pertenecientes a la $\mathrm{Me}-$ sa Capitular y al Arca de la Limosna en Ribagorda. Este inventario de tierras dio como resultado un total de 201 almudadas de labranza pertenecientes conjuntamente a la Mesa Capitular y al Arca de la Limosna. En 1494 se harfa un nuevo inventario y apeo de esta heredad ${ }^{61}$.

-Sotos

En este lugar tenemos constancia de la existencia de al menos dos heredades pertenecientes al Arca de la Limosna.

En 1472 el limosnero Luis de Fuentes compró una yunta de heredad con casas en Sotos, para después cederla al Arca de la Limosna. Diez años más tarde Juan de Priego, vecino de Cuenca y morador en Sotos, vendio media yunta de heredad al Arca, y por las mismas fechas sabemos que Íñigo de Mendoza, comendador de Huélamo, también vendio otra yunta de heredad para la Limosna. Estas tierras hacían un total de 2'5 yuntas de heredad y serfan poco después entregadas a censo a don Ruy Gómez de Anaya, abad de Santiago y canónigo de Cuenca, con cargo de 16 fanegas de trigo anuales de la medida mayor más el diezmo. Pero el 19 de septiembre de 1487 don Ruy Gómez de Anaya solicitó permiso del cabildo para poder traspasar dicha heredad con la misma carga de censo a Alfonso de Balboa, vecino de Cuenca. Don Ruy explicó al cabildo que deseaba efectuar dicho traspaso porque él tenía problemas para labrar las tierras, con lo cual el cabildo conquense aceptó que se llevase a cabo la mencionada ope-

\footnotetext{
${ }^{60}$ Bbidem, leg. 715, $\mathrm{n}^{\circ} 5981$.

${ }^{61}$ Ibidem, leg. 715, no 5983.
} 
ración. Poco después Alfonso de Balboa, a su vez, subarrendarfa dicha heredad de Sotos ${ }^{62}$.

Otra importante heredad que posela en Sotos el Arca de la Limosna era la formada por las tierras y casas que fueron donadas por el canónigo Fernando Yáñez de Escalona, a lo que habria que añadir la media yunta que entrego al Arca el racionero Hernando Muñoz. Todo esto, el 2 de junio de 1473 , se entregó en calidad de censo perpetuo a un vecino de Sotos a cambio de 9 almudes de trigo de la medida menor a pagar todos los años para el día de Santa María de agosto. El 12 de septiembre de 1496 algunos miembros del cabildo catedralicio que actuaban en calidad de visitadores de la Limosna decidieron y aceptaron ceder dicho censo al hijo del vecino de Sotos antes citado, que se obligó a pagar cada año 8 almudes de trigo de la medida mayor más el diezmo, todo ello para la Limosna. Después poseyó esta heredad Juan Martínez de Paniagua, lugarteniente del cura de la parroquia de San Miguel de Cuenca, como sobrino del anterior, y pago cumplidamente durante todo el tiempo que vivio ${ }^{63}$.

-Tondos

Antes de 1436 el Arca de la Limosna ya posera tierras en Tondos, pues el 11 de enero de este año se hizo un inventario y apeo de dichas tierras, las cuales sabemos que estaban entregadas en calidad de censo enfitéutico, recibiendo a cambio el Arca 27 almudes anuales de trigo de la medida menor. El 17 de mayo de 1473 se hizo un inventario y nuevo apeo de las tierras y casas que posela el Arca en Tondos ${ }^{64}$.

Aunque corresponde a una época más tardía, resulta sin duda de excepcional interés para un mejor conocimiento del patrimonio del Arca de la Limosna un libro-registro de censos que fue elaborado por el limosnero Alonso de la Mota en el año 1515, pues en él figuran todos los lugares de la diócesis donde el Arca posera bienes raices entregados a censo perpetuo, y también se indican los almudes de trigo que se percibfan anualmente en concepto de pago por dicho censo. Todas las heredades que figuran en este registro estaban entregadas a censo perpetuo, y el pago se efectuaba siem-

\footnotetext{
${ }^{62}$ Ibidem, leg. 601, n⿳01122.

${ }^{63}$ Bbidem, leg. 601, no 1119.

of Ibidem, leg. 606.
} 
pre en almudes de trigo de la medida menor. El documento lleva por título "Libro del pan de los censos que se deven a la Santa Limosna del año de mill y quinientos y quinze años, seiendo yo Alonso de la Mota el limosnero de la Santa Limosna el dicho año"cs, y a través de él se puede elaborar el siguiente cuadro.

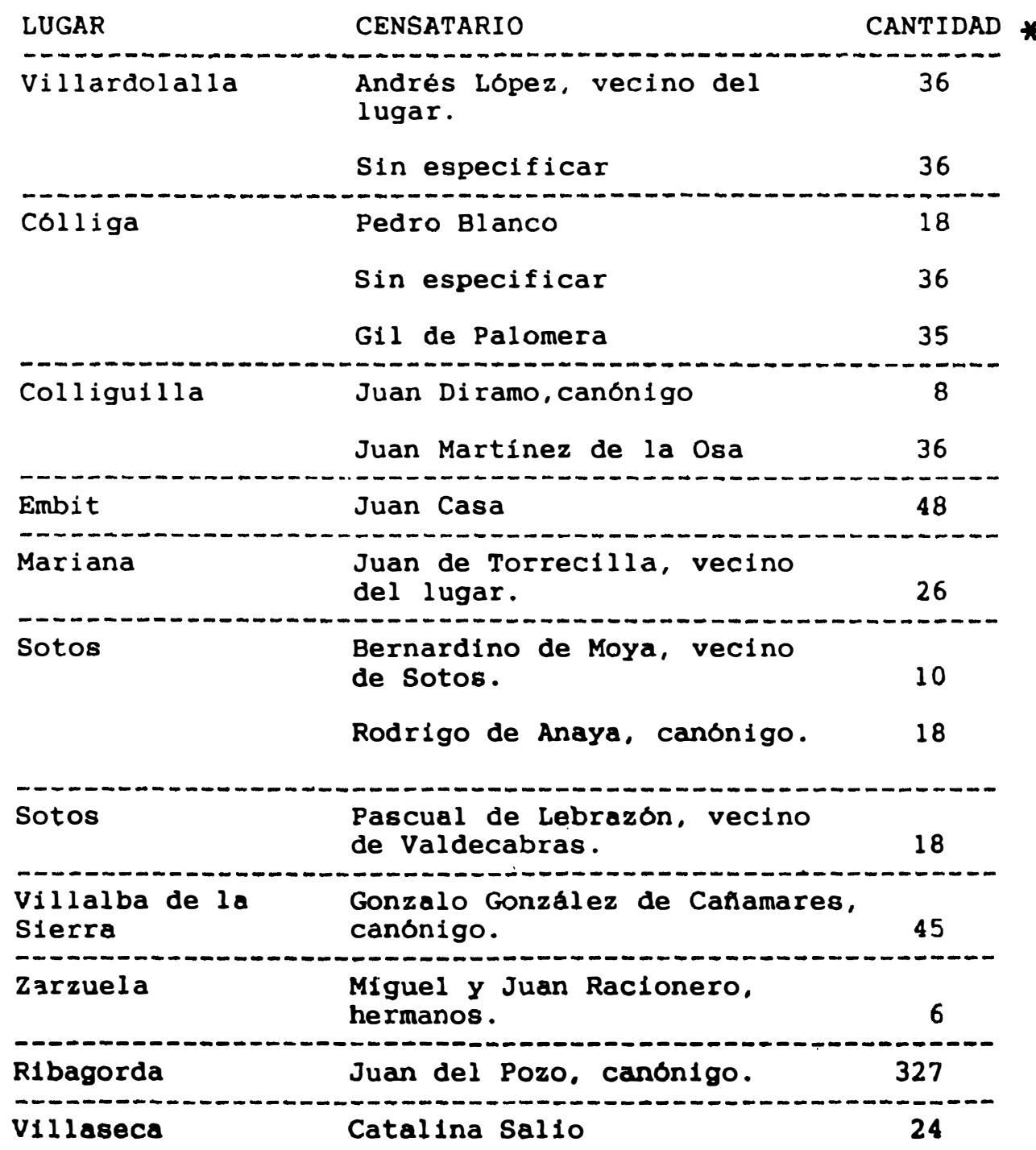

*Esta cantidad se reficre sicmpre a almudes de trigo de la inedida incinor.

${ }^{65}$ lbidem, leg. 782. 


\begin{tabular}{|c|c|c|}
\hline 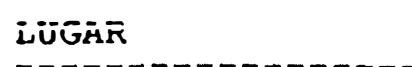 & 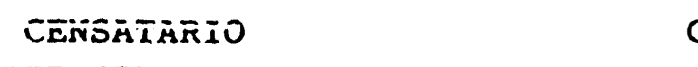 & CANTIDAD \\
\hline Ribatajada & $\begin{array}{l}\text { Andrés Soriano, Miguel de } \\
\text { Aillón y Lope de Huete. }\end{array}$ & 72 \\
\hline \multirow[t]{3}{*}{ Mohorte } & Juan Diramo, canónigo. & $12 \cdot 5$ \\
\hline & Pedro de León, capellán. & 15 \\
\hline & $\begin{array}{l}\text { Gregorio Alvarez de Alcalá, } \\
\text { deán. }\end{array}$ & 19 \\
\hline Bólliga & Alonso Mateo, vecino del lugar. & 22 \\
\hline $\begin{array}{l}\text { Villanueva de } \\
\text { los Escuderos }\end{array}$ & Francisco de Orguz & 30 \\
\hline Jábaga & $\begin{array}{l}\text { Francisco Fernández de } \\
\text { Bólliga, cura de Jábaga. }\end{array}$ & 15 \\
\hline Tondos & Juan Blanco, vecino del lugar. & 33 \\
\hline $\begin{array}{l}\text { Arcos de la } \\
\text { Cantera }\end{array}$ & $\begin{array}{l}\text { Francisco, Fernando } y \text { Luis de } \\
\text { Aillón. }\end{array}$ & 60 \\
\hline Valdecabrillas & Juan de Moya, vecino de Cuenca. & 26 \\
\hline Navalón & $\begin{array}{l}\text { La mujer de Francisco de } \\
\text { Torrecilla }\end{array}$ & 2 \\
\hline $\begin{array}{l}\text { Villar del } \\
\text { Maestre }\end{array}$ & Mi qu & 8 \\
\hline Las Cuevas & Diego de Saelices & 24 \\
\hline Navalón & $\begin{array}{l}\text { El licenciado Acevedo y } \\
\text { Juan de Ocana }\end{array}$ & 15 \\
\hline $\begin{array}{l}\text { Villar de Domingo } \\
\text { Garcia }\end{array}$ & $\begin{array}{l}\text { Los herederos del chantre don } \\
\text { Diego del Castillo. }\end{array}$ & 14 \\
\hline Arrancacepas & Juan de Ferrán Sáiz & 6 \\
\hline \multirow[t]{3}{*}{ Arcas } & El 11 cenciado Carlos & 28 \\
\hline & Alonso de Pareja & 11 \\
\hline & Pedro el Paje & 15 \\
\hline La Cerrajera & Francisco de Albarracín & 30 \\
\hline de Arcas & Tomás Criares & 25 \\
\hline
\end{tabular}




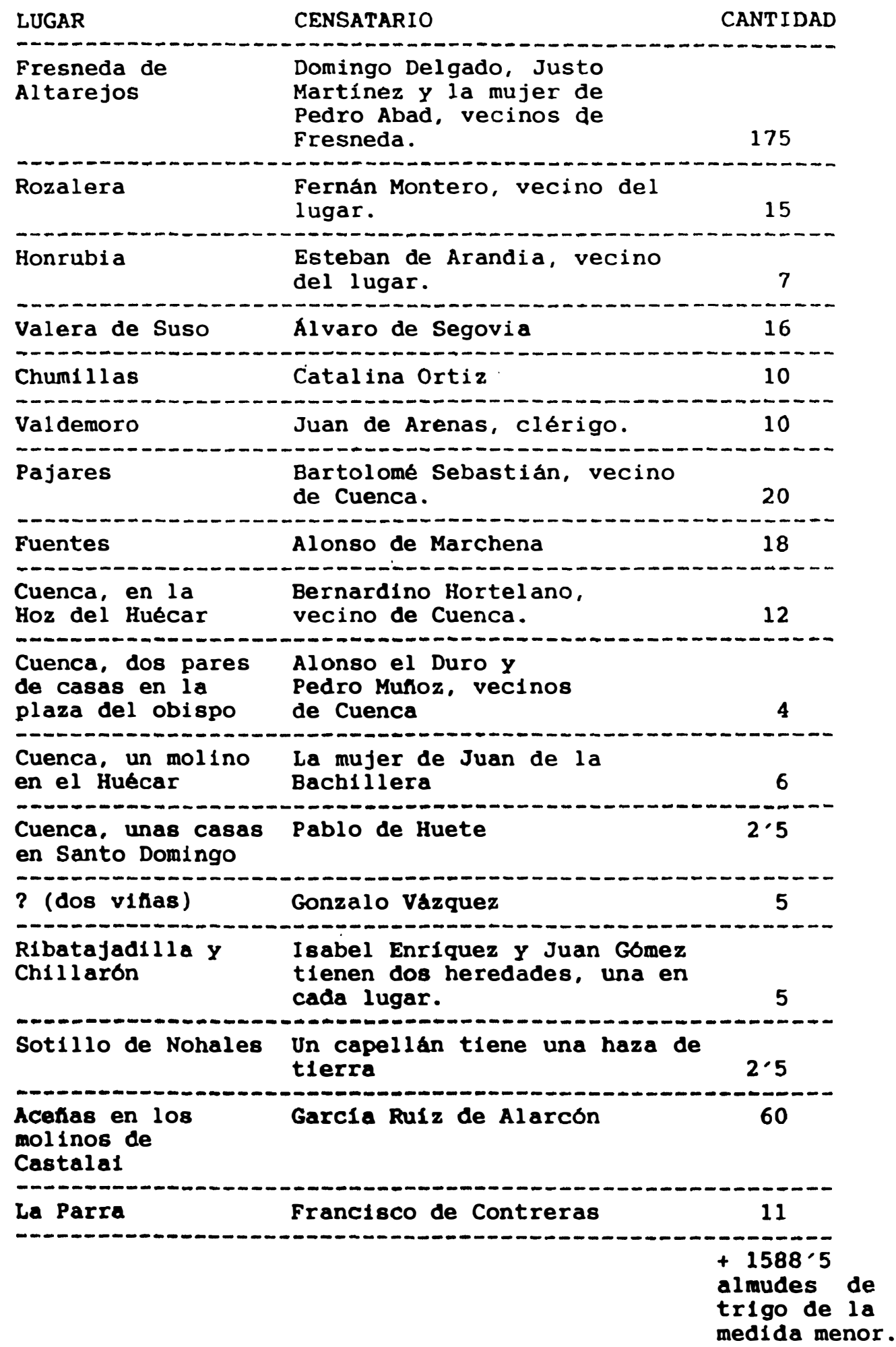


Todos los datos expuestos en las páginas anteriores permiten establecer una aproximación al modo de administración y sistema de explotación de los bienes patrimoniales pertenecientes al Arca de la Limosna.

Este patrimonio se formaría fundamentalmente gracias a las donaciones llevadas a cabo por algunos miembros del cabildo catedralicio de Cuenca y, en menor medida, por los laicos de la diocesis, aunque también contamos con algunos ejemplos de pequeñas ventas al Arca de la Limosna por parte de los laicos. Asimismo, ya a principios del siglo XVI, sucede en varias ocasiones que cuando el Santo Oficio confisca los bienes de ciertas personas que van a ser condenadas parte de dichos bienes se ceden al Arca de la Limosna ${ }^{66}$.

El patrimonio rural será, con mucho, el más predominante. Se trata de heredades que en la mayoría de los casos se encuentran situadas en aldeas muy próximas a Cuenca, y en las cuales se cultiva sobre todo cereal, siendo dentro de este grupo el trigo la especie cerealícola que más a menudo se cita en la documentación. Le sigue en importancia el cultivo de huerta, y puede señalarse la presencia del lino en Sotos. Por otro lado, la documentación nos indica cómo casi todas estas heredades llevaban aneja una o varias casas.

El cabildo catedralicio tenfa dificultades para explotar directamente este patrimonio, y de ello es un ejemplo la heredad de Cólliga, que primero fue abandonada y luego ocupada por campesinos de las zonas proximas, para finalmente ser entregada por el cabildo en calidad de censo perpetuo. Debido a ello, ya desde poco después de instituirse el Arca de la Limosna, el cabildo optaría por un sistema de explotación indirecta, entregando las tierras a censo perpetuo. En la inmensa mayorra de los casos, salvo excepciones, el cobro anual se realizaba en almudes de trigo de la medida menor, que habrian de entregarse para el día de Santa Marfa de agosto. A veces la documentación indica que el trigo debla ser llevado hasta Cuenca y ser depositado en casa del limosnero, oficio que siempre recala en un miembro del cabildo catedralicio, pudiendo ser desde una dignidad hasta un simple racionero.

Aunque casi todos los censatarios serán laicos, en ocasiones también podían ser eclesiásticos, los cuales, a su vez, solían proceder a suba-

${ }^{66}$ AHPC, sección de Desamortización, leg. 92. 
rrendar los bienes de que eran censatarios, aunque también contamos con algún ejemplo de subarrendamientos por parte de laicos.

Cada cierto número de años este patrimonio rural era objeto de inventarios, apeos y amojonamientos para comprobar el número de almudes de siembra de que constaba cada heredad. Estos apeos y deslindes se realizaban sobre todo cuando el cabildo se enteraba de que alguien habra ocupado parte de las tierras pertenecientes al Arca. Como "visitadores" de la Limosna aparecen canonigos e incluso dignidades de la catedral, y su función era la de visitar temporalmente las posesiones del Arca para comprobar su estado de conservación, asi como para tramitar cualquier posible renovación de censo.

Por lo que respecta a los bienes urbanos que pasaron a engrosar el patrimonio del Arca de la Limosna, hay que señalar que en su inmensa mayoria eran casas en la ciudad de Cuenca, muchas de las cuales habian sido donadas al Arca en 1439 por el acaudalado canónigo Martín González. Todas estas casas se explotaban indirectamente entregándolas a censo perpetuo y, si bien durante el siglo XV el pago solía hacerse en metálico, durante la centuria siguiente también se realizará en especie, tal como nos muestra el inventario elaborado en 1515 por el limosnero Alonso de la Mota.

Este sistema indirecto de explotación a veces podía dar lugar a pequeños problemas a la hora de que se llevase a efecto una percepción puntual de la cantidad establecida en el censo. Contamos con algunos ejemplos que nos hablan de la existencia de pequeñas irregularidades en este sentido. Asl, en 1452 el administrador del Arca de la Limosna hará un requerimiento a Ruy Gómez de Anaya, arcediano de Alarcón y lugarteniente del deán, para que mandase a Angel García de Molina, marido de Mari Garcia, heredera de Domingo Garcla, compañero de la catedral de Cuenca, pagar al Arca de la Limosna los dos tlorines de oro que el dicho Domingo Garcla al morir habfa donado para la Limosna, renta que estaba situada sobre unas casas de la Pellejerfa. Finalmente Ruy .Gomez de Anaya darfa una sentencia mandando a Angel García de Molina pagar al Arca los dos florines de oro que le correspond fan $n^{(1)}$.

Otro ejemplo de situaciones conflictivas lo tenemos en la sentencia que el 16 de octubre de 1489 pronunció don Francisco Álvarez de Toledo,

\footnotetext{
${ }^{67}$ Bbidein.
} 
maestrescuela y vicario general del arzobispo en la archidiocesis de Toledo, como juez-árbitro en el pleito que tenía lugar entre Alonso de Fonseca, obispo de Cuenca, y el cabildo catedralicio, por un lado, y Pedro Ruiz de Montealegre, canónigo de Cartagena, por otro. El pleito era sobre ciertas cuentas de la Limosna correspondientes a los años pasados, y de las que el dicho Pedro Ruiz fue receptor. La sentencia será contraria a Pedro Ruiz de Montealegre, al que se condena a pagar al cabildo $40.130 \mathrm{mrs}$ que les debia y que pertencian a la Limosna. Se establece cierto plazo de tiempo para que el pago se lleve a efecto, y en caso contrario se procedería contra los bienes del mencionado canonigo de Cartagena ${ }^{68}$. En este pleito la gravedad del asunto explica que el obispo y cabildo de Cuenca hiciesen un recurso de apelación a la metrópoli toledana, de la que dependfan eclesiásticamente.

Sobre el patrimonio del Arca de la Limosna a principios del siglo XVI resulta particularmente ilustrativo el cuadro elaborado a partir del libro de censos que redactó el limosnero Alonso de la Mota en 1515. Del análisis de estos datos puede inferirse cómo la mayoría de los censatarios del Arca de la Limosna eran laicos, pues de un total de 61 casos en que el nombre del censatario nos es conocido, sólo en diez ocasiones se trata de eclesiásticos: figuran seis miembros del cabildo catedralicio, dos capellanes y dos simples clérigos. Las cantidades a pagar por los censatarios son muy variables, y están en función del valor y extensión de los bienes entregados a censo; asi, van desde los 2 almudes de trigo anuales de la medida menor que pagaba la mujer de Francisco de Torrecilla por ciertos bienes de NavaIon hasta la considerable cifra de 327 almudes que por las tierras de Ribagorda pagaba el potentado canónigo Juan del Pozo, personaje éste de enorme riqueza que se encontraba en la cúpula de la oligarquia urbana conquense de la primera mitad del siglo XVI. La suma de todas las cantidades a entregar al Arca en concepto de censo da un resultado de $1588^{\prime} 5$ almudes de trigo de la medida menor para el año de 1515 , cifra que no debe considerarse en absoluto desdeñable y que nos indica que el Arca de la Limosna posela un patrimonio fundiario de considerable importancia.

${ }^{68}$ Ibidem. 


\section{CONCLuSIÓN}

A lo largo de las páginas precedentes ha quedado perfectamente manifiesto cómo durante el bajomedievo se desarrollo en la ciudad y diocesis de Cuenca todo un proceso de encuadramiento institucionalizador de la asistencia al pobre.

La red hospitalaria urbana que, aún contando con algunos precedentes, se desarrollaría esencialmente durante las dos últimas centurias de la Edad Media, jugará un importante papel en este sentido.

Pero será sin duda el Arca de la Limosna la institución que desempeñe la función de mayor significación, ya durante el siglo XV y, posteriormente, a lo largo de todo el Antiguo Régimen. Nos encontramos ante una sociedad que se plantea el tema de la pobreza no desde la perspectiva de una problemática social, sino como una cuestion moral que entra en el ámbito de lo religioso; de este modo la inquietud del pecado, el temor a la muerte y la incertidumbre de la salvación, elementos claves en la mentalidad teocéntrica de la época, se reflejan en los testamentos y en la atención que los testadores otorgan casi siempre a la ayuda al pobre.

Efectivamente, a través del análisis de los testamentos conquenses se ha podido constatar cómo muchos eclesiásticos, y en particular los miembros del cabildo catedralicio, contribuyeron con importantes donaciones al sostenimiento económico de una institución de carácter caritativo-asistencial como era el Arca de la Limosna, aunque tampoco faltarán las donaciones de laicos. En muchos casos, aunque no siempre, se trata de donantes que forman parte de las capas más altas de la sociedad local; de este modo, la ayuda al pobre a través de la limosna constituye un elemento que contribuye, según la ideología de la época, a facilitar la salvación de los más pudientes.

En definitiva, la pobreza se acepta como un fenómeno necesario e inevitable cuya presencia se justifica por constituir la mejor prueba para el desarrollo de la caridad cristiana. De este modo adquiere pleno sentido el apelativo de "Santa Limosna" que en ocasiones aparece en la documentacion, o el hecho de que, sobre todo durante la Edad Moderna, el Arca de la Limosna reciba la denominación de "Arca de la Limosna de San Julián", estableciéndose de este modo una asociación entre la actividad caritativa hacia los pobres y la labor benéfica atribulda, sin duda con un exceso de idealización, al segundo prelado que ocupó la sede conquense. 
La ciudad de Cuenca, por tanto, aún cuando la mentalidad de la época no considere a la pobreza como un problema social a erradicar, sí verá desarrollarse durante la Baja Edad Media un necesario proceso de control y encuadramiento institucional de la atención al pobre, proceso que se encuentra en consonancia con el que simultáneamente se está produciendo en la Corona de Castilla y en el resto de los reinos de Occidente, y que sentará las bases de su posterior desarrollo y maduración durante la Edad Moderna.

\section{RÉSUMÉ}

Dans la ville et la diocèse de Cuenca, à mesure qu'avance le Bas Moyen Age, se déroulera tout un procès d'institutionnalisation de l'assistance aux pauvres, procès qui avait lieu parallelement dans le reste de Castilla et de l'Occident Médiéval. Le réseau hospitalaire, qui, bien que comptant avec quelques exemples d'époques antérieures, se développera surtout dans le $\mathrm{XIV}^{\mathrm{e}}$ et le $\mathrm{XV}^{\circ}$ siecles, jouera un rôle important dans ce sens, et on peut dire autant des confréries de laïcs qui se sont crées dans la ville de Cuenca, entre lesquelles il faudrait souligner celle de "Saint François, Saint Pierre et Saint Paul". Mais ce sera surtout celle qu'on nomme l'Arche de l'Aumóne (Arca de la Limosna), dépendante du chapitre de la cathédrale, l'institution qui remplira la fonction de plus grande signification deja pendant le $\mathrm{XV}^{\circ}$ siècle et, plus tard, tout au long de l'Ancien Régime. A travers le differents testaments de Cuenca, nous savons que le soutien économique de cette institution fut possible grâce aux donations réalisées par les gens d'église, surtout des membres du chapitre de la cathédrale, et en moindre mesure par quelques laïcs. Tout ceci, à fin de comptes, sera le point de départ du développement postérieur et de l'épanouissement de ce courant d'assistance aux pauvres pendant le Moderne Age.

\section{SUMMARY}

In the city and diocese of Cuenca, a whole process of attention to the poor was developed during the low Middle Ages. This process can be compared to the one that was happening in the rest of Castile and in the Medie- 
val West. The hospital network was developed specially in the XIV and XV centuries, but it had some precedents from earlier times. It played an important role like the lay confraternities in the city of Cuenca. Among them we might point to the "St. Francis, St. Peter and St. Paul" guild. But the institution called the Arca de la Limosna, which depended on the cathedral chapter, was the one that played a very significant role during the XV century and, later, during all the Ancien Régime. From several Cuenca wills, we know that the economic support of this institution was possible thanks to the gifts made by ecclesiastics, specially by members of the cathedral chapter, and by some laymen in a lesser way. In short, all this created support for the later development of attention to the poor during the Modern Age. 